\title{
LOS SEIS ERRORES MÁS COMUNES EN LA INTERPRETACIÓN JURÍDICA ECUATORIANA
}

MOST COMMON SIX ERRORS ON LEGAL INTERPRETATION IN ECUADOR

César Coronel Jones*

Resumen: La finalidad principal de este trabajo, es el de corregir la concepción errónea que tiene la cultura jurídica ecuatoriana de la interpretación de la ley. Para esto, el autor a través de una crítica constructiva, enuncia seis conceptos equívocos aceptados por nuestros juristas, jueces y funcionarios de la administración pública. Asimismo desarrolla un estudio introductorio sobre el propósito de la interpretación de la ley y sus elementos vinculados.

Palabras clave: Hermenéutica jurídica, reglas de interpretación, escuelas exegéticas, equidad, historia jurídica

Abstract: The main purpose of this work is to correct the misconception prevailing in culture of the Ecuadorian legal interpretation of the law. For this, the author through constructive criticism, show six misconceptions quite accepted by our lawyers, judges and public officials. Also develops an introductory study on the purpose of the interpretation of the law and its associated elements.

Key words: Interpretation of the law, interpretation rules, exegetical schools, equity, legal history

* Socio de la firma Coronel \& Pérez (Ecuador). Doctor en Jurisprudencia por la Universidad Católica Santiago de Guayaquil y Máster en Derecho Internacional y Comparado por la Universidad de Georgetown (Washington D. C.). Catedrático de Derecho Civil. Miembro de la Corte de Arbitraje de la Cámara de Comercio Internacional.ccoronel@coronelyperez.com 
Fecha de recepción: 8-09-2007

Fecha de aceptación: 11-11-2007

\section{INTRODUCCIÓN}

Es una extraña paradoja que se dediquen tantos recursos a producir abundante legislación en las más diversas áreas y se haya profundizado tan poco en el análisis de los métodos y técnicas de interpretación jurídica.

El vicio del fetichismo jurídico, que pretende solucionar todos los problemas sociales con la expedición de nuevas leyes, consume energías y recursos inconmensurables, mientras nuestra cultura jurídica languidece anclada al pasado, encadenada al literalismo esclavizante que se asume dócilmente como dogma en los tribunales y despachos administrativos.

Al revisar los antecedentes de este fenómeno cultural, que tanto daño ha causado a nuestro sistema de administración de justicia y que desprestigia el derecho continental haciéndolo parecer rígido y menos adaptable a la dinámica social, he encontrado dos aspectos que deseo relevar: su origen en las enseñanzas de la escuela de la exégesis francesa, superada en ese país hace más de un siglo y la gran similitud que presenta, también en este aspecto, la realidad jurídica ecuatoriana con la de otros países latinoamericanos.

La explicación para lo primero tiene que ver con la brillantez de las exposiciones de los grandes juristas europeos de la escuela exegética y la enorme influencia que ejercieron, tanto directamente, como a través de los tratadistas latinoamericanos del siglo pasado que bebieron en sus fuentes. Lo segundo probablemente tiene que ver no solo con la gran similitud cultural 
de los países latinoamericanos sino también con la comodidad y el facilismo.

El tema de la interpretación jurídica es uno de los más importantes y cruciales en el Derecho, y quizás también uno de los más difíciles, pues como ha señalado Renato Tevez, limita con la filosofía. Lamentablemente, pese a ello, ha terminado mereciendo escasa atención de nuestra doctrina jurídica, que se ha limitado a aceptar los antiguos postulados de la escuela exegética casi sin cuestionamientos, dando lugar así a un estancamiento del sistema jurídico, el cual se ha visto superado por la dinámica social y alejado de los avances en las ciencias, la economía y la cultura.

\section{LA ESCUELA DE LA EXÉGESIS}

Los orígenes de esta escuela, que tanta influencia sigue ejerciendo sobre nuestra cultura jurídica, arrancan del racionalismo francés que inspiró al Código Napoleónico. Según Linares Quintana "el racionalismo jurídico del siglo XVII creyó colmadas sus aspiraciones con la expedición de los códigos y llegó a sostener en un momento dado que la redacción de leyes perfectas, claras y precisas, habría de suministrar soluciones ya hechas a todas las humanas controversias. En esta forma desaparecería el problema de la interpretación ya que los jueces quedarían reducidos a una tarea mecánica y automática que no necesitaría el auxilio de ningún comentarista" (1998, p. 77).

Por su parte García Maynez (2003, p. 333), siguiendo el resumen de dichas doctrinas contenido en la obra de Francoise Geny, relata que la primera vez que se formularon las ideas inspiradoras de dicha escuela fue cuando, en 1841, Blondeau leyó ante la academia de Ciencias Morales y Políticas su memoria titulada 'L' autorité de la loi", en la cual sostenía que las decisiones de los jueces debían fundarse exclusivamente en la ley. 
Dicho jurista admitía la interpretación, pero solo en el sentido de exégesis de los textos. Consecuente con su punto de partida, rechaza "las falsas fuentes de decisión, con las cuales se pretende sustituir la voluntad del legislador" como los precedentes, usos, doctrinas, equidad, etc. Y llega al extremo de sostener que, si el juez se encuentra ante leyes contradictorias que hagan imposible descubrir la voluntad del legislador, debe abstenerse de juzgar, considerar tales preceptos como no existentes y rechazar la demanda.

La idea de que toda interpretación es siempre exégesis de los textos es el principio dominante en las enseñanzas de los grandes juristas de la segunda mitad del siglo XIX, como Demolombe, Aubry et Rau, Laurent y Baudry Lacantinerie, que tanta influencia ejercieron sobre los grandes juristas latinoamericanos como Claro Solar, Alessandri, Somarriva, y otros.

Entre los argumentos invocados en apoyo de esta tesis está la riqueza de la legislación que, según ellos, a partir de las grandes codificaciones y, sobre todo, a partir de la expedición del Código de Napoleón, hace casi imposible la existencia de casos no previstos. Recuerdo a este respecto la escena imaginada en la broma de Ihering, en que un racionalista quedaba sorprendido al entrevistarse con San Pedro al final de su vida terrena y descubrir que había algo no previsto por el Código Civil.

Como para los defensores de la exégesis, la ley es la expresión de la voluntad legislativa, la interpretación de los preceptos legales debe reducirse a la búsqueda del pensamiento de su autor. Esta tarea, cuyo fin último consiste en descubrir la voluntad de los legisladores, es precisamente lo que se llama exégesis. Efectivamente, este sometimiento a la intención del legislador es el rasgo dominante de dicha escuela, como ha señalado con acierto Ducci Claro (2006, pp. 23-25). Hay que seguir paso a paso los textos legales -decía Demolombe- hasta encontrar el pensamiento de quienes los formularon. La interpretación es pues, desde ese punto de vista, aclaración de los 
textos, no interpretación del derecho. "Ignoro el derecho civil, -decía Bugnet-, solo conozco el código de Napoleón".

Por su parte, Laurent expresaba "los códigos no dejan nada al arbitrio del intérprete", pues ya el derecho está hecho, y exclamaba: "Mi profesión de fe, mi divisa es los textos ante todo".

Como ha señalado Julien Bonnecase (1945), esta escuela se caracteriza por el culto del texto de la ley, la búsqueda de la intención del legislador como criterio determinante para efectuar la interpretación y un carácter profundamente estatista, pues considera que el legislador a través de sus actuaciones es virtualmente omnipotente e infalible, al convertir a las leyes en la única fuente de las decisiones jurídicas.

Pero los principios de la exégesis pueden llevar, como sostengo ha ocurrido lamentablemente en nuestro medio, a un verdadero anquilosamiento de la ciencia jurídica, en la que no hay evolución ni creación. Si la tarea del intérprete se reduce a leer los textos y a buscar la intención real o presunta del legislador, lo cual es en muchos casos imposible, la aplicación de las normas se vuelve un ejercicio en el cual el respeto excesivo a los precedentes jurisprudenciales u opiniones doctrinales predomina por sobre la búsqueda de los principios generales que inspiran y deben guiar la ciencia del derecho. En efecto, la sobrevaloración del método gramatical y la búsqueda de la intención del legislador conducen a menospreciar al método lógico y al sistemático e, inclusive, a la aplicación del principio de equidad que debe guiar todo el proceso interpretativo. Más fácil resulta, en la tradición exegética, encontrar un precedente u opinión y darles el carácter de idea general para buscar la solución, que remontarse a los principios jurídicos que inspiran a las instituciones, las cuestiones controvertidas a la luz de los mismos y considerar las realidades sociales actuales, los aportes de la ciencia y la equidad. 


\section{EL PREDOMINIO DE LA ESCUELA DE LA EXÉGESIS EN NUESTRA CULTURA JURÍDICA}

En su magnifica obra sobre Interpretación Jurídica (2006, pp. 97-100), el tratadista chileno Carlos Ducci Claro realiza una reseña de lo ocurrido en su medio apenas promulgado el Código Civil chileno, de enorme similitud con el ecuatoriano, el colombiano y otros, que refleja de muy buena manera lo ocurrido en general en Latinoamérica. Refiere este autor que desde los primeros años de dictado el código, dada la enorme influencia de los grandes comentaristas del código de Napoleón en Chile, la interpretación exegética de la ley fue la doctrina indiscutida por los tratadistas y a través de la enseñanza de éstos, de la jurisprudencia. Agrega que el respeto absoluto por el tenor literal de la ley y el acatamiento de la presunta voluntad del legislador han informado casi toda la jurisprudencia. He aquí algunas de sus referencias perfectamente aplicables al caso ecuatoriano: $\mathrm{Si}$ examinamos los tratadistas de Derecho Civil veremos que ya en 1892 Paulino Alfonso decía: "Si el legislador, a quien debe suponerse suficientemente versado en la materia sobre la cual hace recaer sus disposiciones, y el lenguaje con que las expresa, dijo algo con claridad, será porque quiere que, así como lo dice, se entienda y se practique". "Dejar pues de entender sus disposiciones en el sentido claro que ellas ofrecen, bajo cualquier pretexto, aunque sea en razón de las consecuencias absurdas o perjudiciales a que ello dé lugar, es sublevarse contra la autoridad de la ley, es convertirse en intérprete del legislador". "Provee ese principio a que sea reconocido y acatado el verdadero pensamiento del legislador".

Poco después -en idéntico sentido- se expresaba Manuel Amunátegui Solar: "Dispone el Código que ante todo se atienda al tenor literal cuando el sentido de la ley es claro". "La letra de la ley es, por lo tanto, la expresión del pensamiento del legislador". Más adelante: "El conocimiento de la ley no se podrá alcanzar sino colocándose en el mismo lugar en que se ha encontrado el Ius Humani, v. 1 (2008/9), p. 206 
legislador, sustituyéndose a él y reconstituyendo su propio pensamiento".

Luis Claro Solar expresa: "La obra del intérprete, como hemos dicho, es reconstruir el pensamiento del legislador, y como el legislador ha formulado su pensamiento en un texto, la ley es la expresión del pensamiento del legislador. Cuando la ley es clara, tenemos ese pensamiento netamente declarado, conocemos la intención del legislador por su propia boca y no podemos eludirla; y el juez debe, por graves que sean las consideraciones que se puedan oponer a la ley, aplicarla tal como está escrita". Alfredo Barros Errázuriz y Héctor Claro Salas participan del mismo criterio.

Más recientemente los profesores Arturo Alessandri Rodríguez y Manuel Somarriva han enseñado: "El pensamiento se exterioriza con palabras; si aquél se hace visible en éstas, debe estarse al tenor literal de la ley. Lo contrario sería suponer que el legislador no sabe manifestar sus ideas, que es incapaz de escoger las palabras reveladoras de su pensamiento". Más adelante agregan: "El pensamiento del legislador también puede quedar en evidencia por el estudio de la historia fidedigna del establecimiento de la ley".

Como se sabe, la doctrina de los autores chilenos es utilizada habitualmente en el medio jurídico ecuatoriano tanto en la enseñanza universitaria como por los tribunales en sus fallos. Son frecuentes en nuestro medio los fallos en que se da por aceptado como verdad inconcusa que nuestro Código Civil acepta sin restricciones el método exegético. Así por ejemplo, los fallos publicados en la Gaceta Judicial Año XCV, Serie 16, numero 2, paginas 470 en adelante ${ }^{1}$, en que la Corte Suprema ha dicho que la

1 "QUINTO.- La interpretación de la Ley es un real problema, toda vez que las normas
legales se las formulan en términos generales o abstractos, y por lo tanto hay que
analizar los sistemas que permitan darle a la norma su correcta aplicación a los casos
concretos, de suerte que se obtenga como resultado final la realización del Derecho,
constituyendo un problema lógico que no tiene sin embargo el rigor científico de las
ciencias exactas. Con esta finalidad se han creado diversos métodos, entendiéndose por Ius Humani, v. 1 (2008/9), p. 207 
corriente consagrada en nuestro Código Civil es la exegética, es decir, que atiende exclusivamente al texto de la ley y a las palabras de la ley (Juicio Calvachi contra Director del IESS); y, la sentencia de la sala de lo administrativo de la Corte Suprema publicada en el R.O. 137 del 25 de agosto de 1997 en el caso 149/97².

Las decisiones de nuestros tribunales de instancia y organismos de control, como la Contraloría General del Estado, son igualmente uniformes en dar por aceptado que el método exegético y más aún el mero análisis gramatical del texto de la

tal, los mecanismos para alcanzar el camino verdadero de una materia determinada, tratando de entender la Ley, puesto que se trata de regular la conducta humana en un entorno complejo y variable. SEXTO.- En este orden de cosas, al primer método se lo puede llamar tradicional, cuyo fundamento filosófico es el "Legalismo Utilitarista" de J. Bentham y el racionalismo imperante en el siglo XVIII, logrando su expresión más precisa en la codificación del Derecho Civil Francés del siglo pasado; dentro de estos métodos tradicionales hay tres corrientes: el exegético que atiende exclusivamente al texto legal y a las palabras de la Ley, por lo que se puede llamar método gramatical; el método dogmático que opera a través de procesos deductivos e inductivos $\mathrm{y}$, el método ecléctico que constituiría la combinación de los dos anteriores. Entre los métodos modernos cabe señalarse el histórico evolutivo, el de libre interpretación sistemática, la interpretación finalista y la interpretación integrada. SEPTIMO.- Luego de señalar estos diversos sistemas o métodos es menester concretar, en el Ecuador, cuáles son las reglas de interpretación que están preceptuadas por el Art. 18 del Código Civil, cuyo numeral uno dice: "cuando el sentido de la ley es claro, no se desatenderá su tenor literal, a pretexto de consultar su espíritu". En consecuencia, consagra la corriente exegética como primera regla".

2 "QUINTO.- Al efecto, es necesario analizar las formas de interpretación judicial para dar o no la razón al argumento esfringido, y sobre ello, encontramos que los métodos modernos de interpretación, se apartan del rigor del texto escrito, pudiendo citar a manera de ejemplos, y entre los principales de ellos, el sistema histórico evolutivo, el sistema de interpretación libre, la escuela llamada jurisprudencia de los intereses, la escuela de la interpretación sistemática, los métodos de interpretación finalista o teleológico, y el proceso de la investigación integrado, básicamente. Entre los métodos tradicionales, que encuentran su fundamento filosófico, en el legalismo utilitarista de Bentham y en el racionalismo imperante del siglo XVIII, tuvo auge el llamado exegético, que atiende exclusivamente al texto legal y las palabras de la ley, por lo cual, se lo suele denominar como método gramatical; y, a este sistema se acoge el Código Civil ecuatoriano, cuando en su artículo 18 y bajo el título de interpretación de la Ley, el primer párrafo de la primera regla dice: "Cuando el sentido de la Ley es claro, no se desatenderá su tenor literal a pretexto de consultar su espíritu"."

Ius Humani, v. 1 (2008/9), p. 208 
ley, es el único sistema viable para realizar la interpretación y aplicación de ella. Se trata de una idea tan arraigada en nuestra cultura jurídica, que ha hecho expresar más de una vez la amenaza de que va a plantearse la clausura de las facultades de jurisprudencia y su sustitución por escuelas de lectura y análisis gramatical, si no se reconoce la jerarquía que tiene científicamente la labor de interpretación jurídica.

\section{LA REALIDAD Y LAS FALACIAS}

Pero a pesar de su amplia aceptación entre los juristas, jueces y funcionarios de la administración pública, el método exegético no es asumido ni impuesto por nuestra legislación civil. Por extraño que parezca, este sistema de interpretación, tan arraigado en nuestra cultura, no fue acogido por el genio jurídico de Don Andrés Bello al redactar su famoso proyecto de Código Civil Chileno, que después fuera convertido en Ley en Chile y con ligeras modificaciones en Ecuador y Colombia.

Como ha demostrado documentadamente Ducci Claro (2006), Bello se apartó en esta parte del modelo francés, que no contiene normas sobre interpretación de la ley y se inspiró más bien en el Código Civil de Louisiana, aunque también mejoró considerablemente dicho modelo e implementó el método lógico que busca determinar el sentido objetivo de la ley, como criterio principal en el proceso interpretativo (2006, pp. 95-96).

El propósito de este ensayo es demostrar, inclusive valiéndose del método gramatical, que el Código Civil ecuatoriano no impone la exégesis como criterio interpretativo y que más bien ésta es una de las varias falacias que oscurecen el panorama de nuestra cultura jurídica y que es necesario develar en aras del progreso de la ciencia y de la mejor administración de justicia. 
Se exponen a continuación, seis enunciados que representan algunos de los conceptos más difundidos y comúnmente aceptados en nuestro medio, pese a ser profundamente erróneos, por lo cual no dudo en calificarlos como falacias que petrifican el derecho. Por supuesto, ésta no es una enumeración exhaustiva, ni un análisis completo de un tema de tan enorme envergadura, sino tan solo una muestra de lo mucho que se requiere profundizar en la materia.

(i) Cuando el texto de la ley es claro no puede ser desatendido a pretexto de consultar su espíritu.

(ii) Solo cuando la ley es oscura requiere interpretación. La ley clara no necesita ser interpretada.

(iii) El espíritu, voluntad o intención del legislador debe guiar la interpretación.

(iv) El proceso de interpretación de la ley es la aplicación de un simple silogismo en que se utiliza el método deductivo.

(v) La lógica formal se aplica en la jurisprudencia.

(vi) La equidad solo se aplica supletoriamente.

\subsection{Cuando el texto de la ley es claro no puede ser desatendido a pretexto de consultar su espíritu}

He modificado a propósito el enunciado de la $1^{\circ}$ regla del art. 18 del Código Civil, sustituyendo la palabra "sentido" por el vocablo "texto", para subrayar los excesos a los que ha conducido la adopción del método exegético. En efecto, en la práctica judicial, administrativa y forense, se ha magnificado de tal manera la importancia del análisis gramatical, que se ha tergiversado la propia expresión de la regla y, lejos de buscar el sentido de la ley, se suele limitar todo el análisis a determinar si el texto de la norma es claro. 
Conviene recordar en este punto que Andrés Bello,no acogió la regla del Código Civil de Louisiana, sino que adoptó más bien la regla de que debemos primeramente buscar el "sentido" de la norma.

El Código Civil de Louisiana expresaba:

Art. 13.- Cuando una ley es clara y libre de toda ambigüedad no se puede desatender su letra, bajo el pretexto de seguir su espíritu.

Sin embargo, Bello, pese a que originalmente se inclinó por atenerse a la letra de la ley como criterio básico de interpretación, después abandonó esa opinión y finalmente optó por establecer como criterio hermenéutico la objetividad del sentido de la ley ${ }^{3}$.

Que esta modificación trascendental haya sido consciente o inconsciente es aún motivo de lucubraciones como anota Ducci Claro, quien recuerda que Jiménez de Azúa ha calificado el episodio como producto de una "anticipación genial" del iluminado jurista (Ducci Claro, 2006, p. 92).

Lo cierto es que el proyecto de Bello, que luego se convirtió en ley en Chile y, en Ecuador es la $1^{\circ}$ de las reglas de nuestro art. 18 del Código Civil, reza:

Art. 18.1.- Cuando el sentido de la ley es claro, no se desatenderá su tenor literal, a pretexto de consultar su espíritu.

3 “«(...) Nosotros creemos que lo más seguro es atenerse a la letra; que no debemos ampliarla o restringirla, sino cuando de ello resulten evidentes absurdos y contradicciones; y que todo otro sistema de interpretación abre ancha puerta a la arbitrariedad, y destruye el imperio de la ley». Este párrafo explica la razón de introducir las normas que regulan la interpretación. En cuanto a los otros conceptos su sensibilidad varió. Veremos otra nota en que su criterio está más cercano a la idea de buscar la voluntad del legislador. Constataremos, por último, cómo en las normas precisas abandonó como criterio fundamental tanto la literalidad de la ley como la voluntad presunta del legislador, para establecer, consciente o intuitivamente como base hermenéutica, la objetividad del sentido de la ley" (Ducci Claro, 2006, pp. 91-92). 
Esta preeminencia del sentido de la ley ordenada por el texto de nuestro Código implica una enorme diferencia con el primitivo método gramatical. Mientras este último pretende hacer consistir la interpretación en un análisis gramatical, el nuestro, que llamaremos método lógico, consiste en buscar su sentido, es decir, la verdad intrínseca del precepto.

Naturalmente, esto no significa despreciar o menospreciar la importancia del elemento gramatical, pero tampoco reducir o limitar a ello la labor interpretativa.

Por supuesto que el análisis gramatical es importante y siempre lo será en la labor interpretativa, pero es solo el primer estadio de la misma.

Como decía Giuvencio Celsio, "No consiste el entender las leyes en retener sus palabras, sino sus fines y efectos".

Esto se hace patente al considerar que, en su esencia, la interpretación jurídica, especialmente la interpretación judicial, es la labor de aplicación de la ley al caso concreto $\mathrm{y}$, en consecuencia, la individualización del derecho a una situación de la vida. No se trata de una simple aplicación indiscriminada de una proposición gramatical. La labor del intérprete es, por su naturaleza, creadora o al menos re-creadora del derecho, pues, como señala Kelsen, "por precisa que la norma general pretenda ser, la especial, creada por la aplicación del tribunal, siempre añadirá a aquélla algo nuevo". Piénsese que cualquier orden, por sencilla que sea, puede ser aplicada de muy diversas maneras.

La búsqueda y determinación del sentido de las normas es una labor de enorme trascendencia y contenido. Los textos son fórmulas linguiísticas que buscan comunicar ideas $\mathrm{y}$, como ha señalado con acierto García Maníes, el problema capital de la teoría de la interpretación es saber qué debe entenderse por sentido de la ley.

El sentido de la ley es su inteligencia, significado o alcance (acepción $10^{\circ}$ del Diccionario de la RAE) y justamente por la importancia central que tiene la operación intelectual de 
determinarlo, ella debe ser realizada utilizando al menos los cuatro métodos de interpretación: gramatical, histórico, lógico y sistemático, y no como han sostenido algunos autores, acudiendo primero al método gramatical y solo después, uno a uno, a los demás ${ }^{4}$.

En otras palabras, el juez no puede por el solo elemento gramatical decidir si el sentido de la ley es claro, sino que debe necesariamente verificarlo recurriendo a los otros métodos interpretativos, pues es dicho proceso lo que le permitirá determinar su verdadero sentido. Una sentencia de la Corte Suprema chilena, redactada por el ministro Oswaldo Illanes, publicada en la Revista de Derecho y Jurisprudencia, tomo 56, Serie Primera, p. 207, trae unos cuantos párrafos que iluminan cuál debe ser la permanente actividad del intérprete:

"Pero para buscar el pensamiento y los móviles del legislador y, finalmente, la verdad jurídica, es menester que el intérprete use cuatro elementos; gramatical, lógico, histórico y sistemático.

No sólo, entonces, el juez debe analizar las palabras de que se ha servido el legislador, sino las relaciones que unen todas las palabras del articulado sobre el punto que se trata, la situación jurídica existente a la época en que se dictó la Ley objeto de la interpretación y, por último, posesionarse de la acción ejercida por ella en el orden general del derecho y el lugar que en este orden ocupa el precepto que se intenta interpretar.

$\mathrm{Y}$ estos cuatro elementos estudiados en conjunto, han de adaptarse a la práctica y a la realidad, para que se cumpla con los fines que se propuso el legislador y encontrar enseguida la verdad jurídica.

Que este método de interpretación de la ley se halla perfectamente consagrado en el art. 19 del Código Civil, si se recuerdan sus términos y sus conceptos. A su tenor literal, si el sentido es claro; es decir, cuando el pensamiento del legislador no ofrece dudas; pero si

\footnotetext{
4 “Así, Don Luis Claro Solar en sus famosas explicaciones de Derecho Civil Chileno y comparado expresa "más si la ley es obscura, habrá que recurrir forzosamente a los otros elementos de interpretación" y después agrega "si esta comparación de las diversas partes de la ley no ponen suficientemente en claro la intención o pensamiento del legislador habrá que completarla" (Ducci Claro, 2006, pp. 92-93).
} 
existe una expresión obscura, es necesario recurrir al pensamiento, sus fines, a través de la lógica, la historia, del sistema legal reinante, de la práctica y de la realidad.

Y así, de este modo, se habrá logrado obtener los verdaderos principios del derecho aplicable a un caso en el cual la idea del legislador no aparece, por el uso de vocablos obscuros, suficientemente clara" .

Esta magnifica sentencia, que explica en forma muy clara la necesidad de que concurran los diversos métodos de interpretación, hubiera sido perfecta si en lugar de referirse "al pensamiento -móviles-, fines del legislador" se hubiera referido directamente al sentido de la ley, pues es el sentido objetivo de la norma y no este inaprensible concepto de la intención del legislador, el criterio rector impuesto por el art. 18 del Código Civil.

La interpretación es un proceso intelectual mucho más complejo que la simple lectura o el análisis gramatical de un texto. Interpretar es justamente descubrir el sentido que encierra la ley. Lo que se interpreta no es la materialidad de los signos, sino el sentido de los mismos, su significación (cfr. García Máynez, 2003, p. 327). Es por ello que calificamos como una falacia el afirmar que cuando el texto o tenor literal de la ley es claro éste no puede ser desatendido a pretexto de consultar su espíritu. Todo lo contrario, por claro que sea el tenor literal de la ley, es siempre necesario emplear los diversos métodos de interpretación hasta lograr determinar con la mayor precisión posible cuál es su verdadero sentido o inteligencia.

Ya Aftalión subrayaba a propósito de la complejidad de las operaciones intelectuales que implica el proceso de interpretación, que todos los métodos tienen como rasgo común la pretensión de constituir la receta infalible, "pero" ocurre que en los hechos ninguno de los métodos tradicionales ha demostrado ser capaz de desplazar totalmente a los otros, lo que se pone de

5 Jurisprudencia citada por Carlos Ducci Claro (cfr. 2006, pp. 93-94).

Ius Humani, v. 1 (2008/9), p. 214 
manifiesto cuando se repara en que se han ido acumulando más que reemplazando, de lo que es buena prueba el caso relativamente frecuente, de los jueces y doctrinarios que para reforzar sus conclusiones, invocan la concordancia de los resultados obtenidos por los más diversos procedimientos metódicos (en Linares Quintana, 1998, p. 88).

\subsection{Solo cuando la ley es obscura requiere interpretación. La ley clara no necesita ser interpretada}

Pero el principio de la preeminencia del sentido de la ley no ha sido de manera alguna la regla general aceptada por nuestros tribunales, sino que por el contrario, se ha sostenido que la claridad de la ley debe juzgarse meramente por su tenor literal. Ejemplo de ello son las dos sentencias ya citadas en que la Corte Suprema ecuatoriana así lo ha dicho.

En igual sentido en Chile, se ha sostenido "si la ley no contiene precepto oscuro alguno, debe aplicarse según su tenor literal y no se puede acudir para ese fin a su historia, intención o espíritu. No cabe interpretar la ley perfectamente clara pues toda interpretación presupone que exista oscuridad (Revista de Derecho y Jurisprudencia, tomos 6, 23, 26).

También en otro fallo se ha dicho "frente al claro tenor literal de la ley es inútil e ilegal tratar de interpretar" (Revista de Derecho y Jurisprudencia, tomo 35) y finalmente que "cuando el tenor de la ley es claro resulta inoficioso averiguar si su contenido guarda o no armonía con los principios generales, puesto que la misión del tribunal consiste en aplicar la ley escrita, cualesquiera que sean sus consecuencias o las circunstancias especiales del caso fallado (Revista de Derecho y Jurisprudencia, tomos $33 \mathrm{y}$ 39).

La gran mayoría de nuestros tribunales, y muchos otros de Latinoamérica, siguen venerando aquella falacia expresada en el aforismo in claris non fit interpretatio, y sostienen que la ley clara no requiere ser interpretada. Pero, como ya hemos señalado, esto 
parte de una errónea apreciación de en qué consiste la interpretación, la cual no es una mera operación intelectual de conocimiento, sino por el contrario, una operación normativa, especialmente cuando hablamos de interpretación judicial o administrativa, destinada a disciplinar la vida social.

El intérprete, especialmente el judicial o administrativo, no puede limitarse a señalar lo que la ley dice, sino que, ante la presencia de un caso concreto que le está encomendado a su resolución, debe realizar una valoración del precepto para decidir cuál es su razón de ser y su sentido.

Una primera consideración que debemos realizar es que la propia calificación de una ley como clara, es ya el resultado de un proceso interpretativo. Si a esto se agrega que lo importante en la norma, dada su naturaleza y finalidad de reglar la vida social, no es su expresión gramatical (que no es más que un conjunto de signos a través de los cuales se persigue expresar ideas), coincidiremos en que no podemos limitarnos a interpretar solamente aquellas leyes cuyo tenor parezca oscuro. Aun habiendo claridad en la expresión de la ley, es siempre indispensable considerar la época en que fue dictada, pues el lenguaje tiene una carácter esencialmente evolutivo y las mismas palabras suelen tener un significado diferente después de unos años. Por otra parte, si la ley tiene carácter normativo y parte necesariamente de la estimación de conductas típicas o casos promedio abstractamente imaginados, es obvio que en la vida real los casos concretos que deban ser decididos por el juez o funcionario administrativo pueden presentar circunstancias diferentes a las que fueron imaginadas y previstas en la norma y esto por diversos motivos: a) Porque la ley tiene un largo tiempo de aplicación y frecuentemente estamos aplicando códigos y leyes que fueron redactados hace docenas de años y hasta siglos, cuando las circunstancias históricas ni siquiera permitían imaginar los eventos a los que la norma iría a ser aplicada; b) porque ni el más erudito y brillante legislador puede haber previsto todos los casos 
que se presenten en la vida real. Como ha dicho con acierto Max Ascoli, "La realidad es violadora de toda norma". "Si los hechos humanos pudiesen penetrar exactamente en los esquemas que los preceden, la vida perdería la infinita individualidad en que se fracciona; sería cristalizada, aprisionada, no más vida" (en Ducci Claro, 2006, p. 106). Y es que, en definitiva, la labor de interpretación y aplicación del derecho, ni es ni puede ser mecánica como añoraban Napoleón y los exégetas, sino que, por el contrario, como ha señalado Recaséns Siches, "la acción inteligente de la jurisprudencia es descubrir nuevos sentidos e insospechados alcances en añejas normas, cuando estos tienen que proyectarse sobre realidades muy diferentes que las de antaño" (1973).

Si entendemos adecuadamente la enorme significación de la labor interpretativa, que en definitiva entraña la aplicación de la norma al caso concreto, debemos necesariamente acordar que resulta esencial que no nos detengamos en el análisis de una formula lingüística que busca comunicar ideas, sino que más bien acudamos a la determinación de tales ideas y verifiquemos que ellas no contradicen el ordenamiento jurídico y que, por el contrario, se coordinan con éste, como lo recomendaba acertadamente Pérez Guerrero al explicar que el método sistemático es siempre de obligatoria aplicación 6 .

No es pues, bajo ningún análisis serio, aceptable, que la ley clara no requiera ser interpretada. Se trata no solamente de una falacia sino también de una ingenuidad.

\subsection{El espíritu, voluntad o intención del legislador, debe guiar la interpretación}

La doctrina exegética preconiza que la labor de interpretación debe procurar recomponer el pensamiento del

\footnotetext{
${ }^{6}$ Ver fallo No $734-98$ emitido por la Primera Sala de lo Civil y Mercantil de la Corte Suprema de Justicia, publicado en el Registro Oficial № 103 del 7 de enero de 1999.
} 
legislador. Esta idea se encuentra fuertemente arraigada en la doctrina de los autores latinoamericanos y de los tribunales de justicia; sin embargo, es virtualmente imposible cumplir con semejante cometido.

El legislador normalmente no es una sola persona, sino un cuerpo colegiado, por lo que en los hechos la ley es producto no de una sola voluntad o intención, sino de múltiples voluntades que luego del debate parlamentario han llegado a un acuerdo que se recoge en un texto determinado. A esto debe agregarse que en el proceso de formación de la ley generalmente intervienen varios organismos o funciones del Estado, como el ejecutivo, que debe expresar su aprobación u objeciones a los proyectos de la función legislativa.

Por otra parte, con el paso del tiempo, la voluntad o intención que originó la ley suele perder relevancia por estar totalmente desfasada con la problemática sobreviniente.

Hacer depender el alcance de los preceptos jurídicos de un factor subjetivo y, en muchos casos, realmente ficticio, sería introducir un elemento de profunda incertidumbre en el proceso interpretativo, pues siendo virtualmente imposible saber de cierto lo que los autores de la ley tenían en mente, se puede concluir atribuyéndoles intenciones imaginarias que violen el sentido objetivo de la norma. Esta voluntad mítica del legislador no puede ser admitida como criterio rector de la interpretación jurídica. Y es que la ley no es la manifestación de un deseo del legislador, sino esencialmente una norma de conducta; por ello, solamente es obligatorio el contenido de la ley y no su proceso de formación; una vez promulgada, ella se separa de su autor y adquiere una existencia objetiva. Con mucha razón se ha dicho que el interprete "esta obligado a conocer y entender las leyes mejor que las mismas personas que intervinieron en su redacción; a sacar más de la ley de lo que estas personas pusieron conscientemente en ella, al redactarlas o aprobarlas" (Radbruch, 1974, pp. 24-25). 
Lo que realmente interesa es determinar cuál es el sentido de la ley, que es el objeto real de la interpretación y, si examinamos con detenimiento las normas del Código Civil, es ese el criterio que nos imponen las reglas del art. 18. En efecto, nada hay en dicha disposición que se refiera a la voluntad o intención del legislador, salvo que se la quiera ver en la referencia a la historia fidedigna del establecimiento de la ley que se hace en el inciso segundo del numeral primero del art. 18. Aparte de esta referencia nada se dice sobre el dogma exegético de que debe buscarse la intención del legislador.

En cambio, hay sólidas razones fundadas en el texto de estas normas para sostener que lo que se privilegia para buscar el sentido de la ley, cuando éste no estuviere claro, es la intención o espíritu, manifestados en ella misma.

$\mathrm{El}$ inciso segundo del numeral primero del art. 18, siguiendo fielmente la propuesta de Bello, dice: "Pero bien se puede, para interpretar una expresión oscura de la ley, recurrir a su intención o espíritu claramente manifestados en ella misma, o en la historia fidedigna de su establecimiento (...)".

Y es así como al adaptar el Código de Lousiana, Bello introdujo una modificación sustancial evitando la obligatoriedad de su interpretación gramatical e incluyendo el concepto del sentido de la ley. Al tratar del elemento intención o espíritu es claro que Bello optó por imponer que se busque la intención o espíritu objetivo de la ley, al punto que el texto indica que se debe recurrir a la intención o espíritu de la ley claramente manifestados en la misma norma.

Como se comprenderá, esta innovación introducida por Bello es fundamental, pues permite que la interpretación pueda tener un carácter constructivo y creador, adecuando las instituciones a los cambios del medio social y realizando una interpretación progresiva de la ley, reconociendo el carácter de la norma que está destinada a reglar conductas sociales por largo tiempo. 
Se ha querido sostener que la clara distinción entre "sentido" y "tenor literal" que menciona el inciso primero del art. 18, queda desvirtuada por la disposición del inciso segundo del mismo artículo que indica: "Pero bien se puede, para interpretar una expresión oscura de la ley, recurrir a su intención o espíritu claramente manifestados en ella misma, o en la historia fidedigna de su establecimiento (...)". Esto es totalmente inexacto, pues la oscuridad a que se refiere esta disposición no es la oscuridad del tenor literal sino la del sentido de la ley. El vocablo "expresión" que se emplea en el inciso segundo no tiene el significado de "término" o "palabra, sino el de "oración" o discurso, en cuanto manifestación escrita de una idea, precepto o razonamiento.

\subsection{El proceso de interpretación de la Ley es la aplicación de un simple silogismo en el que se utiliza el método deductivo}

Tradicionalmente se ha enseñado que la ley es la premisa mayor de un silogismo al cual acompaña el hecho o conducta humana que esta siendo materia de análisis o juzgamiento, como premisa menor; luego se produce como conclusión el efecto o consecuencia previsto en la propia ley.

Esta manera de concebir el proceso de interpretación y aplicación del derecho es una exagerada simplificación que no se compadece de la realidad y que debemos descartar a fin de revalorizar y reconocer el profundo significado e importancia que tiene el proceso interpretativo. Si bien es cierto que en un sentido teórico la interpretación es sólo un proceso intelectual que consiste en explicar o declarar el sentido de textos faltos de claridad (Diccionario de la RAE, acepción uno), no es esa la labor de interpretación jurídica que por excelencia están llamados a realizar los jueces y funcionarios administrativos y los mismos abogados. Los jueces no se limitan a explicar o declarar el sentido de los textos legales; en realidad tienen a su cargo una tarea mucho más trascendente que es la de aplicar el derecho determinado frente al caso concreto, lo cual es la norma de 
conducta obligatoria; para ello, deben realizar un importante procedimiento de raciocinio jurídico, que empieza por seleccionar cuáles son las normas jurídicas aplicables y cuál es su sentido, después de calificar cuáles son los hechos relevantes o más importantes del caso que se presenta para su juzgamiento; luego se concluye si las normas seleccionadas se aplican o no al hecho que se juzga.

Si se mira con atención el proceso de aplicación del derecho, se podrá apreciar que en él solamente hay una apariencia de silogismo, pues en realidad el juez establece todos los antecedentes por un proceso ajeno a la deducción, ya que él es quien escoge las premisas sobre las cuales va a fundar su sentencia. La premisa mayor la selecciona al determinar cuál es la norma aplicable, ya que muchas veces hay más de una norma de posible aplicación, o ésta se encuentra establecida en varias disposiciones legales; luego, el juez también va a fijar cuál es el alcance o sentido de la norma que él ha considerado como aplicable, pues lo normal es que una disposición legal tenga varios sentidos o alcances posibles o, inclusive, razonables, y es el juez quien debe escoger cuál es el adecuado. Finalmente, el juez también está encargado de establecer la premisa menor, al determinar y calificar cuáles son los hechos más relevantes y que van a determinar la conclusión. Como se puede apreciar, la conclusión siempre depende de la forma en que el juez establezca estas premisas y en consecuencia, el proceso de interpretación no es sólo lógica formal ni simple silogismo, sino algo mucho más complejo.

$\mathrm{Si}$ aceptamos sin restricciones aquella falacia de que la interpretación jurídica se reduce a la aplicación de un silogismo de lógica formal, estaremos desconociendo la riqueza del proceso y la realidad del mismo. La ley no es nunca un derecho directamente aplicable; es sólo uno de los elementos del contenido de la sentencia o decisión que es la que contiene fuerza ejecutiva, el derecho aplicado directamente. La norma legal no es una 
proposición válida por sí misma, sino que está encaminada a producir determinados efectos; no es un principio físico válido, cualesquiera que sean las consecuencias que produzca, como lo es la ley de la gravedad. Por eso es que el juez, ante una norma aparentemente aplicable, debe ver si se cumple su razón o espíritu frente al caso específico. Si no se cumple, debe abandonar la norma o valorizar su sentido de modo de llegar a un resultado justo, pues como ha dicho Karl Engish “(...) lo importante son los procedimientos de que el juez debe valerse para formular las premisas (...)," lo que nos lleva a analizar la quinta falacia.

\subsection{La lógica formal se aplica en la jurisprudencia.}

Ahora bien, si es imposible un procedimiento de lógica formal, ¿qué clase de razonamiento puede emplear el intérprete? Recaséns Síches ha dicho con acierto que "El pensamiento jurídico es un pensamiento sobre problemas que deben resolverse sin dejarse influir por una preconcebida doctrina total (....)".Y en la misma línea de pensamiento, Heck ha expresado que "El problema jurídico se debe aprender como una cuestión abierta, ponderar comparativamente los puntos de apoyo de todas las soluciones posibles, así como también de las objeciones correspondientes y alcanzar finalmente las soluciones (...)". Como se trata de un debate en el que hay varias soluciones posibles debe empezarse por la argumentación, que es el tipo de razonamiento empleado por el jurista. A este respecto, el profesor Ducci, citando a Chain Pedleman en su obra Tratado de la Argumentación, ha señalado esclarecedoramente que "en la argumentación la verdad la constituyen las opiniones relativamente más seguras y mejor experimentadas porque tienen su sentido en lo verosímil, lo plausible y lo probable. La razón, examinando los juicios que la fundamenta, decidirá cual es la tesis más plausible." Si tenemos presentes estas realidades comprenderemos por qué es imposible que llegue a cumplirse la aspiración de que los jueces sean sustituidos por computadoras, 
como lo fue en su momento la ilusión de Napoleón Bonaparte de que no fueran necesarios comentarios al Código Civil francés.

\subsection{La equidad solo se aplica supletoriamente}

Otra falacia sobre la interpretación jurídica es la de sostener que la equidad solo se aplica supletoriamente, esto es, en el caso de que ningún otro de los métodos pueda ser aplicado. Otra vez, el origen de esta tesis es justamente la esclavitud al texto de la ley, que lamentablemente prima en nuestra cultura jurídica. Veamos cómo se desarrolla esta idea y las razones por las cuales debe ser desechada.

El principal argumento reside en que el número 6 del articulo 18 del Código Civil indica: "En los casos en que no pudieren aplicarse las reglas de interpretación precedentes, se interpretarán los pasajes oscuros o contradictorios, del modo que mas conforme parezca al espíritu general de la legislación y a la equidad natural". El texto de la propia ley, se argumenta, establece que solamente en los casos en que no sea posible aplicar las reglas de interpretación precedentes, a saber, la aplicación de los elementos lógico, gramatical, histórico y sistemático, es que puede aplicarse la equidad natural y, ello, respecto de los pasajes oscuros o contradictorios, nada más.

Un segundo argumento parte de la equivocada apreciación de lo que es la equidad, oponiéndola al derecho, como si fuera cosa distinta y contraria y que se puede aplicar solo en supuestos excepcionales. Ambos argumentos son falaces, pero antes de pasar a rebatirlos, conviene detenerse a señalar que la norma se remite "al espíritu general de la legislación y a la equidad natural". Coincidimos con esa remisión, pues ambos conceptos deben servir, no solamente como criterios para interpretar, sino también para realizar el proceso de integración del derecho. Así, por ejemplo, ante la falta de normas detalladas sobre el proceso de formación del consentimiento en materia civil, consideramos perfectamente razonable y procedente que se apliquen las que 
sobre esta materia existen en el Código de Comercio. Así se ha fallado acertadamente en Chile, donde existe una situación similar.

Pasando al análisis de fondo, éste es un típico caso en que debemos buscar primordialmente el sentido de la norma y buscar la coherencia del mismo dentro del sistema, para determinar el alcance de la disposición. Si la ley dispone que debemos acudir a la equidad natural como criterio interpretativo cuando no se puedan aplicar las otras reglas ¿sería admisible que, en cambio, cuando se puedan aplicar dichas reglas se admita como válida una interpretación que conduzca a un resultado inicuo, no equitativo? Obviamente, la respuesta es negativa. Sería un absurdo que la ley admitiera que con la aplicación de los elementos gramaticales, lógicos, históricos y sistemáticos, pudiera darse la aberración de un resultado alejado de la equidad natural. Si por principio lo que la ley busca es la realización de la justicia, si, por definición, la equidad no es si no la realización de la justicia, aún a falta de ley positiva es inadmisible dicha conclusión.

El verdadero problema arranca del concepto de equidad, de lo que entendemos por ella, y qué tan opuesto o contradictorio puede ser este concepto a lo justo en derecho. Es cierto que la tercera acepción del Diccionario de la RAE la define como "Justicia natural, por oposición a la letra de la ley positiva", y que la quinta acepción indica que es la "Disposición del ánimo que mueve a dar a cada uno lo que se merece", pero no debemos caer en el equívoco de considerar que la equidad es algo alejado o extraño a la ley. Todo lo contrario; filosóficamente, la equidad no es más que "la consideración de un caso particular para darle una solución adecuada a sus circunstancias particulares" (Ducci Claro, 2006, p. 79). Como dice Aristóteles en su Etica Nicomaquea, "Lo equitativo y lo justo son una misma cosa; y siendo buenos ambos, la única diferencia que hay entre ellos es que lo equitativo es mejor aún (...) la ley necesariamente es siempre general, y hay ciertos objetos sobre los cuales no se pueden estatuir 
convenientemente por medio de disposiciones generales (...)". "Lo propio de lo equitativo consiste precisamente en restablecer la ley en los puntos en que se ha engañado, a causa de la fórmula general de que se ha servido" (en Ducci Claro, 2006, p. 158).

El profesor Recaséns Siches, en su ensayo sobre el tema, al explicar la voz equidad en la Enciclopedia Jurídica Omeba, tomo $\mathrm{X}$, sintetiza con gran claridad el significado de las acepciones del término:

Son varias, aunque no independientes ni antagónicas las acepciones de la palabra equidad.

Una de estas acepciones es equivalente a justicia. En este sentido, se entiende por equidad lo fundamentalmente justo. Al fin y al cabo la palabra equidad expresa una de las dimensiones de la idea de justicia, a saber, el principio de igualdad o proporcionalidad. En tal sentido, justicia y equidad resultan vocablos sinónimos.

Una segunda acepción, la más usada e importante, de la palabra equidad es la de denotar una norma individualizada (sentencia judicial o resolución administrativa) que sea justa, es decir, que resulte justa en el caso particular y concreto para el que se dictó. En este sentido se suele hablar de equidad como de aquello que el juez debe poner en práctica para lograr que resulte justa la conversión de la norma genérica y abstracta de la ley en la norma concreta e individualizada de la sentencia dictada para un caso singular.

En tercer lugar, se habla también de equidad para designar la norma o el criterio en que deben inspirarse las facultades discrecionales del juez o del funcionario administrativo.

Ahora bien, de las tres acepciones indicadas en que se usa la palabra "equidad", la más importante es la segunda. En efecto, se entiende ante todo y sobre todo por equidad aquel modo de dictar sentencias judiciales y resoluciones administrativas mediante el cual se tome en cuenta las singulares características del caso particular, de suerte que en vista de éstas se interprete y aplique con justicia la ley, la cual está siempre redactada en términos abstractos y generales. Este es el sentido de la palabra equidad que ha suscitado especiales estudios y el que todavía en el presente requiere algunos esclarecimientos, pues en este tema se ha incurrido en graves confusiones por pocos autores. (...)". 
Lamentablemente, algunas de nuestras leyes aún promueven el equívoco y no pocos tribunales han incurrido en la aberración de admitirlo. Así, el Código de Procedimiento Civil mantenía la norma, hoy inaplicable, del artículo 1009, según el cual, la Corte Suprema de Justicia podía fallar equidad y no sacrificar la justicia por la mera omisión de formalidades legales: "Los magistrados de la Corte Suprema de Justicia, en las sentencias y autos con fuerza de sentencia, cuando dicha Corte actúe como tribunal de instancia, tendrán la facultad de aplicar el criterio judicial de equidad, en todos aquellos casos en que consideren necesaria dicha aplicación, para que no queden sacrificados los intereses de la justicia por sólo la falta de formalidades legales". Como si fuera acaso admisible, que los otros tribunales sí la pudieran sacrificar...

Por su parte, nuestros tribunales en más de una ocasión han concluido que ante el texto claro de la ley, ellos deben aplicarlo aunque se produzca un resultado contrario a la equidad. Y en las dependencias administrativas y en los organismos de control, como la Contraloría General del Estado, esto es moneda común y principio dominante. Los ejemplos abundan y merecen un volumen entero de anecdotario.

Pero lo cierto es que la equidad es la manera correcta de interpretar las leyes, absolutamente todas. Es la manera de entenderlas y tomarlas como base para elaborar las normas individualizadas. En todos los casos, sin excepción.

Esto se comprende fácilmente cuando se analiza la función creadora del derecho que le corresponde a la labor interpretativa.

El orden jurídico positivo consta no solo de normas generales como la constitución y las leyes, sino también de normas particulares como las establecidas en contratos y estatutos de asociaciones similares, por ejemplo. Pero además y, fundamentalmente, de normas individualizadas y concretas como las sentencias judiciales y resoluciones administrativas; de hecho, como anota con agudeza Recaséns Siches, las normas generales de los códigos y leyes se fabrican para que en su día, cuando sea 
necesario, puedan existir sentencias y resoluciones. Las únicas normas perfectas e individualizadas son las que constan en sentencias o resoluciones que pueden ser inexorablemente impuestas, mientras que las leyes, por una esencial necesidad del proceso de aplicación, son siempre una obra inconclusa, pues sus términos abstractos requieren ser concretados en la norma individualizada. Ahora bien, esa individualización debe siempre estar guiada por el criterio de razonabilidad, que es lo que constituye en su esencia la equidad. El juez debe siempre interpretar la ley de la manera que lleve a la conclusión más justa y, al hacerlo, lejos de alejarse del ordenamiento jurídico, dará a éste su más perfecto cumplimiento.

Mucho queda por decir sobre interpretación jurídica y las particularidades que en ella se imponen en las diferentes áreas del derecho, pues las materias constitucional, penal, laboral, administrativa y otras, poseen singularidades que implican principios particulares a ellas; sin embargo, las reflexiones contenidas en este breve ensayo pueden servir como estudio introductorio. 


\section{REFERENCIAS}

Aristóteles. (s. IV a.C.). Etica Nicomaquea.

Bonnecase, J. (1945). Elementos de Derecho Civil (tomo I). México: Editorial José M. Cajica Jr.

Corte Suprema de Justicia, caso 149/97 (R.O. 137 de 25 de agosto de 1997).

Corte Suprema de Justicia, fallo 734-98 emitido por la Primera Sala de lo Civil y Mercantil (R.O. 103 de 7 de enero de 1999).

Corte Suprema de justicia, fallos publicados en la Gaceta Judicial Año $\mathrm{XCV}$, Serie 16, numero 2, págs. 470 y ss.

Ducci Claro, C. (2006). Interpretación Jurídica. Santiago de Chile: Editorial Jurídica de Chile.

García Máynez, E. (2003). Introducción al Estudio del Derecho. México: Porrúa.

Linares Quintana, S. (1998). Tratado de Interpretación Constitucional. Buenos Aires: Abelado-Perrot.

Radbruch, G. (1974). Introducción a la Filosofía del Derecho (trad. Wenceslao Roces, 4a edición). Madrid: Fondo de Cultura Económica. Madrid.

Recaséns Siches, L. (1973). Nueva Filosofía de la interpretación. México DF: Porrúa.

Revista de Derecho y Jurisprudencia. Santiago de Chile. 